\title{
A Preliminary Assessment of Hyperspectral Remote Sensing Technology for Mapping Submerged Aquatic Vegetation in the Upper Delaware River National Parks (USA)
}

\author{
Slonecker Terrence ${ }^{1 *}$, Kalaly Siddiq², Young John33, Furedi Mary Ann', Maloney Kelley5, \\ Hamilton Don', Evans Richard6, Zinecker Elizabeth ${ }^{7}$
}

${ }^{1}$ U.S. Geological Survey, National Civil Applications Center, Reston, Virginia, USA

${ }^{2}$ U.S. Geological Survey, Earth Resources Observation and Science Center (EROS), Sioux Falls, South Dakota, USA

${ }^{3}$ U.S. Geological Survey, Leetown Science Center, Kearneysville, West Virginia, USA

${ }^{4}$ Western Pennsylvania Conservancy, Harrisburg, Pennsylvania, USA

${ }^{5}$ U.S. Geological Survey, Leetown Science Center, Wellsboro, Pennsylvania, USA

${ }^{6}$ National Park Service, Beach Lake, Pennsylvania, USA

${ }^{7}$ U.S. Geological Survey, Eastern Geographic Science Center, Reston, Virginia, USA

Email: *tslonecker@usgs.gov

How to cite this paper: Terrence, S., Siddiq, K., John, Y., Ann, F.M., Kelley, M., Don, H., Richard, E. and Elizabeth, Z. (2018) A Preliminary Assessment of Hyperspectral Remote Sensing Technology for Mapping Submerged Aquatic Vegetation in the Upper Delaware River National Parks (USA). Advances in Remote Sensing, 7, 290-312. https://doi.org/10.4236/ars.2018.74020

Received: September 14, 2018 Accepted: December 11, 2018 Published: December 14, 2018

Copyright (c) 2018 by authors and Scientific Research Publishing Inc. This work is licensed under the Creative Commons Attribution International License (CC BY 4.0).

http://creativecommons.org/licenses/by/4.0/

\begin{abstract}
Hyperspectral remote sensing of submerged aquatic vegetation is a complex and difficult process that is affected by unique constraints on the energy flow profile near and below the water surface. In addition, shallow, winding, lotic systems, such as the Upper Delaware River, present additional remote sensing problems in the form of specular reflectance, variable depth and constituents in the water column and sometimes extremely weak signal strength due to absorption and scattering in the water column that can be statistically overwhelmed by the reflectance from upland vegetation in any individual image scene. Here we test hyperspectral imagery from the Civil Air Patrol's (CAP), Airborne Real-time Cueing Hyperspectral Enhanced Recon (ARCHER) system in the scenic waters of two National Parks on the Upper Delaware River. A number of unique image processing problems were encountered, including specular reflectance from winding lotic systems, variable depth and flow dynamics of the riverine environment, and disproportionate signal strength from surface reflectance in this riverine environment. These problems were solved by applying a specular reflectance removal algorithm, applying field data collections to classification results and masking upland vegetation so as to not statistically overwhelm the weak reflectance signal from surface and near-surface water. Much was learned about conducting imaging spectrosco-
\end{abstract}


py in such difficult conditions. Important results include successful mapping of Submerged Aquatic Vegetation (SAV) presence/absence, advantages of upland masking of the reflectance signal, and a number of processing approaches that are unique to this environment. In this paper we summarize our results and identify unique issues that must be addressed in this environment.

\section{Keywords}

Hyperspectral Remote Sensing, Submerged Aquatic Vegetation, Lotic Systems, Hyperspectral Processing Methods, Didymo germinata

\section{Introduction}

The Delaware River is home to two national parks, the Delaware Water Gap National Recreation Area (DEWA) and the Upper Delaware National Scenic and Recreation River (UPDE), which are critically important areas for numerous species habitats, a major source of drinking water for the New York metro area and supporting a variety of recreational activities. The 125 miles of the river that run through UPDE and DEWA National Parks are classified as Special Protection Waters that have "exceptionally high scenic, recreational and ecological values." Under the regulations applicable to this category, "no measurable change in existing water quality [is permitted] except towards natural conditions." [1]. The two parks are located near the common borders of the States of Pennsylvania, New Jersey and New York. See Figure 1.

The Delaware River and its natural resources are of primary importance to UPDE and DEWA, whose enabling legislations cite the need to protect the water quality and scientific features of the river. Aquatic vegetation plays an integral role in the river's ecosystem. Aquatic vegetation serves as a food source and microhabitat for stream invertebrates [2] [3], provides critical feeding and cover habitat for fish [4], and helps to slow flowing waters, filter sediment, and remove nutrients from the water column [5]. Several species of concern in UPDE and DEWA, including the dwarf wedge mussel (Alasmidonta heterodon), and bridle shiner (Notropis bifrenatus), utilize SAV beds during stages of their lifecycle. Furthermore, SAV provide critical habitat and many ecosystem services [6] [7] and these include wave attenuation and hydraulic resistance [8] [9], sediment stabilization and trapping, biogeochemical cycling, and nutrient uptake [10]. SAV beds provide important habitat not only for economically important species such as shrimp and scallops in estuarine and coastal areas but also serve as a nursery for juvenile species that spend only a portion of their life history in these protective beds [11]. Anadromous fish such as American Shad and other alosids rely on submerged aquatic vegetation (SAV) beds for shelter and for foraging insects and other food sources, as they migrate to the freshwater reaches of streams and rivers to spawn [12] [13]. Natural allelopathic properties have led to 


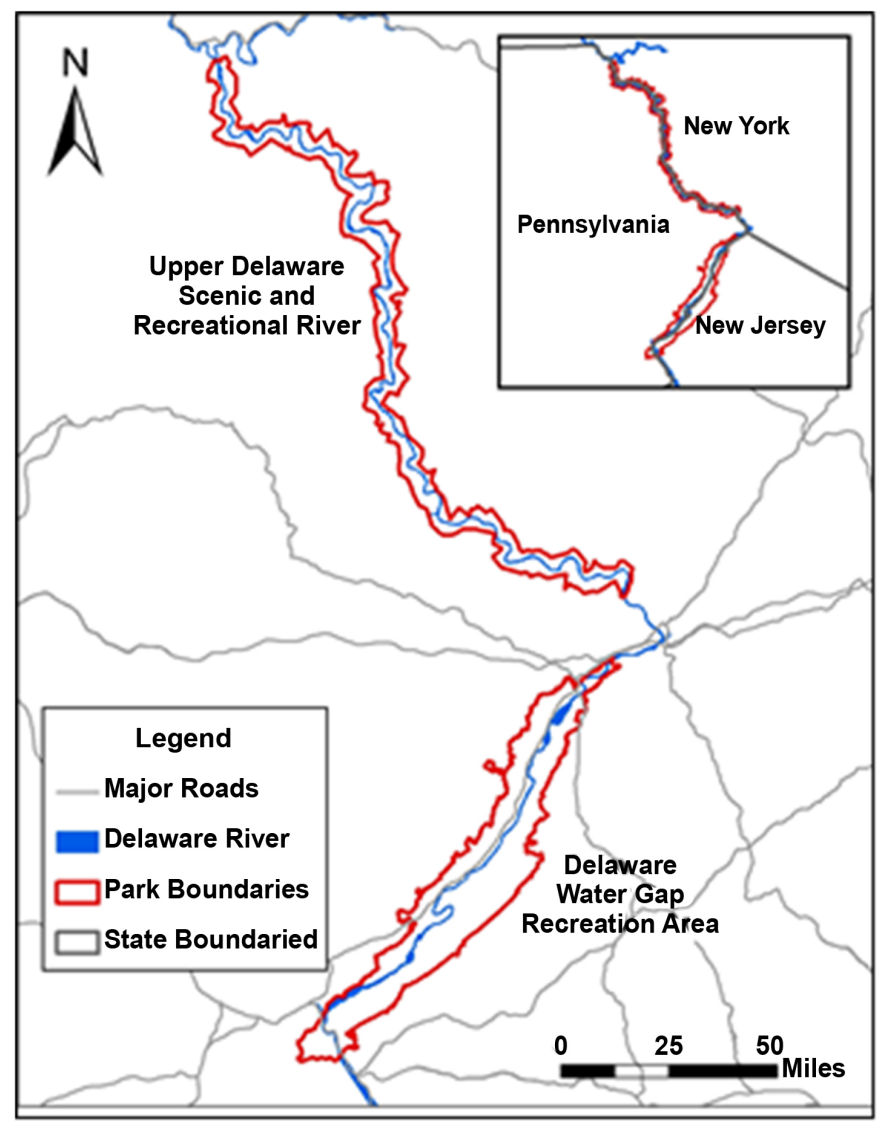

Figure 1. The Upper Delaware Scenic and Recreational River (UPDE) and Delaware Water Gap (DEWA) National Parks.

research that has identified antimicrobial properties in SAV species that may be vital to plant and organismal health [14].

Invasive species are another area of acute concern for national park managers. Invasive aquatic plants cause disruptions to native wetland and flood plain ecosystems, and pose threats to the viability of rare, native species. Both parks have noted a number of new invasive aquatic species that have either been documented in the park [15] or are believed to be nearby. Recently, the nuisance freshwater diatom known as Didymo (Didymosphenis geminata) has been documented in two tributaries and in the mainstem of the Delaware River (New York and Pennsylvania). Blooms of Didymo can form dense blanketing growth on river bottom substrate that may smother or displace macroinvertebrate populations, potentially including the endangered dwarf wedge mussel, and reduce habitat available for salmonid and other fish reproduction. Other threats, such as climate change, domestic and industrial water use, upland land development, and natural gas extraction, may affect water quantity and quality and thereby alter the distribution, abundance, and composition of SAV beds.

As a result, assessments of aquatic vegetation are important indicators of riverine ecosystem integrity, can alert National Park Service (NPS) managers to water quality degradation and eutrophication, and can document the presence of 
invasive aquatic plants that can cause disruptions to native aquatic ecosystems and pose threats to the viability of rare, native species.

\subsection{Remote Sensing of Aquatic Vegetation}

Aerial photography has long been used to map riverine environments, but traditional systems lack the spectral range necessary to identify SAV species differences, and multispectral satellite sensors (e.g. Landsat) lack the spatial resolution necessary to map narrow riverine environments. Advanced sensors have recently become available that now provide the fine spatial and spectral resolution required to map riverine habitats. Hyperspectral sensors image in tens to hundreds of discrete spectral wavelength bands and can be used to identify individual species by comparison with characteristic spectral signatures collected with field or laboratory spectrometers. Recent investigations have established the theoretical basis for spectral mapping of aquatic vegetation [16] and have proven the potential for mapping riverine habitats using hyperspectral imagery [17] [18] [19] [20]. Additionally, advances in bathymetric LiDAR systems are finding application in riverine environments for mapping channel depth, form, and physical habitat [21] [22]. Combining high resolution hyperspectral imagery with LiDAR shows great promise for assessing and monitoring the entire riverine environment [23]. However, very few studies have been conducted in the heavily vegetated rivers of the eastern U.S., and these systems may pose special challenges for mapping. More research is needed in eastern U.S. rivers to investigate these approaches for mapping aquatic macrophytes, algae, and the presence of aquatic invasivespecies and to address the influence of sunglint (specular reflectance), water depth, clarity, flow and substrate on optical properties of hyperspectral and LiDAR imagery. The clear-flowing, relatively shallow Delaware River is uniquely well-suited for testing these emerging technologies. The purpose of this research is to provide an initial assessment of the feasibility and accuracy of advanced remote sensing technologies as a monitoring methodology in riverine systems. The purpose of this research is focused on the study of the spectral reflectance of submerged aquatic vegetation, including invasive species in the two national parks in the Upper Delaware River.

\subsection{Spectroscopic Analysis of SAVs}

Spectroscopy is essentially the science of measuring the interaction of energy with matter and is a fundamental form of remote sensing. Spectroscopy has been used extensively in chemistry and astronomy for material identification and, with the development of new instrumentation, is being increasingly utilized in traditional remote sensing investigations. The spectral reflectance of vegetation has long been a topic of remote sensing interest and the spectral analysis of vegetation stress was the subject of early laboratory spectroscopic and remote sensing imaging research [24] [25]. More recent studies have successfully identified spectral signatures of heavy metal stress and applied these techniques to ap- 
plications involving mineral prospecting and environmental contamination [26]. Spectral reflectance of vegetation and other landscape conditions has received renewed interest by the remote sensing community since the 1990s because of the development of a new class of imaging technology called hyperspectral remote sensing (HRS), also known as imaging spectroscopy. Many of the early and definitive studies in spectral reflectance utilized spectroscopic measurement instruments in a laboratory setting. These instruments measured reflected energy in numerous bandwidths across the electro-magnetic spectrum (EMS) and produced a plot of energy reflectance versus bandwidth, called spectra, which could then be analyzed using standard techniques. HRS not only collects information about reflected energy in very narrow bandwidths, but also collects imagery in the same part of the solar electromagnetic spectrum as other multispectral remote sensing instruments. The result is a digital file of numerous, usually 50 220 of bands of imagery, sometimes called a "cube", (Figure 2) that can be analyzed visually but can also be analyzed with the same spectroscopic methods as laboratory spectra and can identify certain compounds, materials and conditions based on the interaction of photons with the molecular structure of the target material. Spectroscopic analysis techniques can now be employed outside of the laboratory through the use of HRS imaging techniques and portable field spectrometers.

Accurate mapping of aquatic resources, such as wetlands and in particular SAV species located in fresh water bodies, estuaries and coasts, is now more critical than ever [27] [28]. SAV has been identified as a declining aquatic resource of global importance [28] [29]. The value, geographical extent, and ecology of submerged vascular plants are well documented [30]. While few studies have applied hyperspectral remote sensing to investigate submerged aquatic vegetation, rarer still is literature pertaining to the study of SAV in lotic systems. Williams et al. [31] developed an initial successful mapping application of

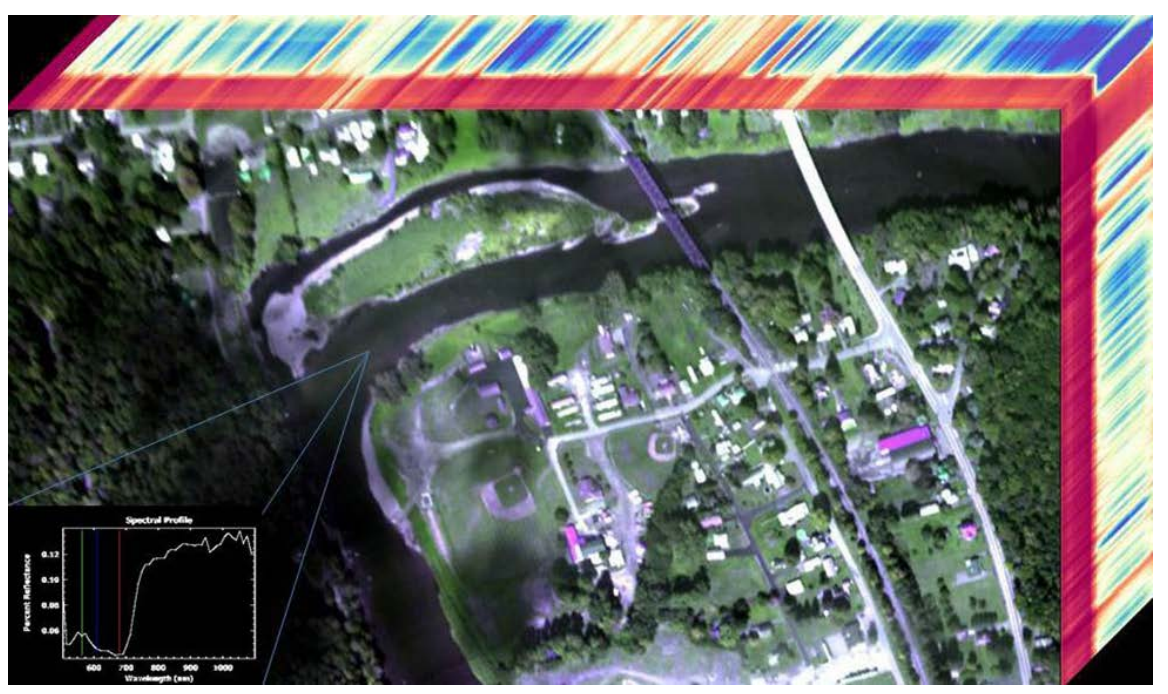

Figure 2. A hyperspectral image cube of the Delaware River near Hancock, New York. The inset shows spectra from the river displaying vegetation features. 
hyperspectral imagery for two types of SAV in the tidal Potomac River. Bolstater et al. [32] used hyperspectral data analysis of SAVs to show that there was a "submerged vegetation red edge" that was evident in the 695 - 700 nanometer (nm) range in vegetation in shallow waters. Underwood et al. and Hestir et al. [33] [34] successfully mapped invasive aquatic vegetation in the Central Valley in California, using hyperspectral HyMap imagery and employing a spectral mixture analysis classification approach. Markus [18] and Legleiter [17] successfully demonstrated the utility of hyperspectral imagery for identifying and mapping in-stream morphology and habitat in riverine systems.

The detection and mapping of aquatic vegetation in these systems presents several inherent problems for hyperspectral analysis. First, infrared energy is almost completely absorbed by the water column and the reflectance from visible bands is greatly reduced by light attenuation in the water column so that many of the traditional vegetation indices generated from ratios of infrared and visible hyperspectral bands are unusable for SAV. Second, silt, sediment, detritus and other particulate matter in the water column can be highly variable and interfere with the reflected signal. Third, variable surface characteristics of flowing water such as pools, riffles and runs create different reflective surfaces and complicate reflective response. Fourth, variable depth of the water column creates different habitat, vegetation, and substrate reflectance profiles. Fifth, specular reflection, also known as sunglint, is an inevitable complication in winding rivers where the sun angle, relative to the water column, is constantly changing. Finally, low level aircraft acquisition of hyperspectral data, over winding rivers, especially with the ARCHER system, is problematic and creates many partial subscenes that require additional preliminary processing and run the risk of altering the characteristics of the original reflectance data.

\subsection{Imaging Spectroscopy of Submerged Aquatic Vegetation (SAV) in Lotic Systems}

Most remote sensing studies concerned with distinguishing wetland vegetation note that wetland vegetation have the greatest variation in spectra in the red edge and near infrared parts of the electromagnetic spectrum [35]. Evident by the limited literature, many variables exist that make it challenging and limit the success of detecting and mapping SAV with the use of imaging spectroscopy. These variables can be generalized into two broad categories: technical and environmental.

The main technical factors that challenge the successful detection of SAV are spatial and spectral resolutions of imaging spectrometers [36] [37]. Specifically, identifying key bands out of several tens of bands, and determining the optimal pixel size for SAV detection are crucial to eliminating band redundancy and improving target detection, respectively. Becker et al. [36] statistically identified eight out of the original 48 spectral band hyperspectral image cube in the VIS-NIR, which contained enhanced spectral differentiation power for classification of Great Lakes coastal wetland SAV species. In order of importance, these 
bands are centered at $685.5,731.5,939.9,514.9,812.3,835.5,823.9$ and $560.1 \mathrm{~nm}$ respectively. The 812.3 and $823.9 \mathrm{~nm}$ bands are noted as being specifically important for the identification of the unique spectral reflectance patterns of SAV. Becker et al. [37] also investigated few different spatial resolutions in an effort to determine the optimal pixel dimension for SAV detection with hyperspectral imagery. They reported that pixel dimensions below $5 \mathrm{~m}^{2}$ were crucial for accurately mapping SAV in their study area, because mixed pixels are reduced. Importantly, current imaging spectrometers are limited because the number of bands requires reducing the spatial resolution during image acquisition and vice versa. The ability to identify SAV with a reduced number of spectral bands allows for investigators of SAV to acquire spectroscopic imagery with finer spatial resolution, which in turn improves the accuracy of identifying and mapping SAV on a species level.

Environmental factors, such as ambient water turbidity, water level above the plant surface, water depth, channel width, sun and view angle, weather conditions and differing phenological states of the SAV species over different segments of the image, make the identification and mapping of SAV extremely challenging in lotic systems, because they impact their spectra variably over both space and time. Underwood et al. [33] in an attempt to map the invasive SAV water hyacinth (Eichhornia crassipes) using imaging spectroscopy data reported that water variably absorbs infrared radiation, which limits the ability to spectrally detect the many invasive SAV species. Moreover, ambient water turbidity, especially containing chlorophyll and floating algae, have spectral features in certain wavelengths that are similar to SAV, and can lead to SAV classification inaccuracy [31] [33] [34]. Williams [31] reported that epiphyte colonization and sediment coating of the SAV leaf surface obscures the unique biochemical signatures of SAV, and thus, impedes identification of SAV by their spectra. Underwood et al. [33] specifically noted that a high ratio of water to SAV, turbid water, and water level above the plant surface were limiting factors in their efforts to detect SAV. In addition, river channels and waterways, which are usually narrow, compared to the resolution of most sensors, limit the ability to investigate SAV in lotic systems, because mixed pixels are introduced (high spatial resolution required $<5 \mathrm{~m}$ ). Furthermore, besides the challenges in mapping SAV in a single image, broader ecosystems present more challenges. Such as, changes in the sun angle between flight lines (i.e. range of acquisition times), inconsistency in water spectra, large tidal differences across ecosystem, water quality differences (turbid water spectra are similar in many wavelengths to that of SAV), local weather conditions, along with potentially differing phenological states of the species over different parts of the image (across nutrient, flow, or latitudinal gradients). Hestir et al. [34] also noted various factors that limit the mapping of SAV using hyperspectral remote sensing such as weather conditions, the sun and view angle, and the bidirectional reflectance distribution function (BRDF), which limits spectral identification of SAV species. 


\section{Data and Methods}

\subsection{Hyperspectral Imagery Acquisition and Processing}

Hyperspectral remote sensing data were collected using the Civil Air Patrol's (CAP) Airborne Realtime Cueing Hyperspectral Enhanced Reconnaissance (ARCHER) system between July 2011 and September 2012. ARCHER is a hyperspectral data collection, analysis, and visualization system developed for the Civil Air Patrol [38]. It combines cutting-edge hyperspectral imaging technology with advanced real-time data processing capabilities for analyzing an object's reflected light. The system uses a special camera that faces down through a quartz glass portal in the belly of the aircraft, which is typically flown at a standard mission altitude of 2500 feet [800 meters $(\mathrm{m})$ ], at 100-knot (50-meters per second) ground speed and results in imagery with 1-m spatial resolution. A typical ARCHER image swath is approximately one meter long and 500 meters wide. ARCHER combines a visible and near-infrared hyperspectral imaging system, a high-resolution visible panchromatic imaging sensor, and an integrated geo-positioning and inertial navigation unit; the navigation unit is capable of acquiring and correcting data onboard and in real time, precisely geo-registering collected imagery [38]. Although several hyperspectral over-flights were conducted, this paper focuses only on the mission that was flown on July 23, 2011 because it coincided with a peak in the Didymo bloom that year. One of the lessons learned from this exercise is that collecting low-level imagery of a winding riverine system is very difficult and several re-flights had to be accomplished because of missed sections of the river.

Raw radiance imagery was downloaded from the ARCHER system and consisted of two simultaneously collected image segments, one high spatial resolution $(0.5 \mathrm{~m})$ panchromatic image and one 52-band $(1.0 \mathrm{~m})$ hyperspectral image. Imagery was converted from radiance to apparent reflectance using proprietary ARCHER mission processing software called GeoRegARCHER, developed by the Space Computer Corporation (Los Angeles, California). This software also uses location data from on-board GPS and navigational systems to geo-register each imagery segment to a UTM coordinate system. Imagery was then processed to correct for atmospheric effects using the Quick Atmospheric Correction module (QUAC) [39] in the Environment for Visualizing Imagery (ENVI) (Exelis Visual Information Solutions, Boulder, Colorado). Reflectance units for each image were divided by 10,000 using a band math expression in order to create float images in percent reflectance units.

\subsection{Field Data Collection}

A project map of UPDE and DEWA was developed using ArcGIS ArcMap 10.2 that included river information (boundaries, mileage, and depth), park boundaries, public lands, public river recreational access areas, and SAV polygons created from Kunsman's survey efforts in 1994 [6]. Given that field sampling would occur during generally low flow conditions in UPDE and DEWA and that 
much of this portion of the Delaware River is bordered by private lands, it was important to examine the distribution of previously defined SAV beds and their relationship to public access points. Based on this analysis, we developed a list of SAV beds and their associated access points that could be reached either by wading or with a shallow bottom boat. River access points were visited in June 2012 to verify accessibility and finalize the list of potential SAV bed targets.

Protocols for vegetation sampling were developed following NatureServe's accepted natural heritage sampling methodology for the quantitative characterization of plant communities [40]. The main difference was the plot size used. Instead of the standard $5 \mathrm{~m} \times 5 \mathrm{~m}$ plot for herbaceous species, a $1 \mathrm{~m} \times 1 \mathrm{~m}$ sampling quadrat was employed. The quadrat size corresponded to the pixel size of the hyperspectral imagery collected so that vegetation data could be used to both document and characterize SAV beds and train and interpret imagery. This size quadrat was also easier to transport and deploy in potentially swift river current. The quadrat was constructed from PVC pipes and fitted with foam so that it could float on the water surface while the surveyors looked down into it to collect data.

Depending on the size of the SAV bed and accessibility, the boundaries of the bed were first identified prior to vegetation sampling. Once the area of the bed was defined, multiple plots were sampled that represented the variation in vegetation found in each bed. Within each plot, the vegetation was visually divided into six strata to account for the variable growth of species in the water column: benthic, rooted submersed, non-rooted submersed, rooted floating-leaved, non-rooted floating-leaved, and emergent. The percent cover was estimated for each species in each stratum using modified Braun-Blanquet cover classes [40] [41]. (Cover classes included 1 or few, occasional, $<5 \%, 5 \%-12 \%, 13 \%-25 \%$, $26 \%-50 \%, 51 \%-75 \%$, and $76+$ ). Specimens of species not identified in the field were collected for later identification and destroyed after identification. In addition to floristic information, the following environmental variables were recorded in each plot: water depth $(\mathrm{cm})$, water velocity $(\mathrm{m} / \mathrm{sec})$, turbidity $(\mathrm{cm})$, and percent substrate composition. Site and survey information was also recorded such as date, time, and names of surveyors, locationcode, plot code, and plot location. A sub-meter GPS unit was used to record both the location of the center of plot and all survey data in a database created for the project. Figure 3 shows an example of the SAV bed plots in the Delaware River used in this project.

\subsection{Specular Reflection and Sunglint Removal}

After some initial data processing attempts with standard hyperspectral tools, it became apparent that there were specular artifacts in the data set. Sunglint or specular reflection is the solar radiation from the water surface that is directly reflected toward the sensor that can subdue or obscure the weak radiance leaving the water column [42] [43] [44] [45]. Sunglint was confirmed by visually examining some of the infrared bands individually. Since these bands should be 


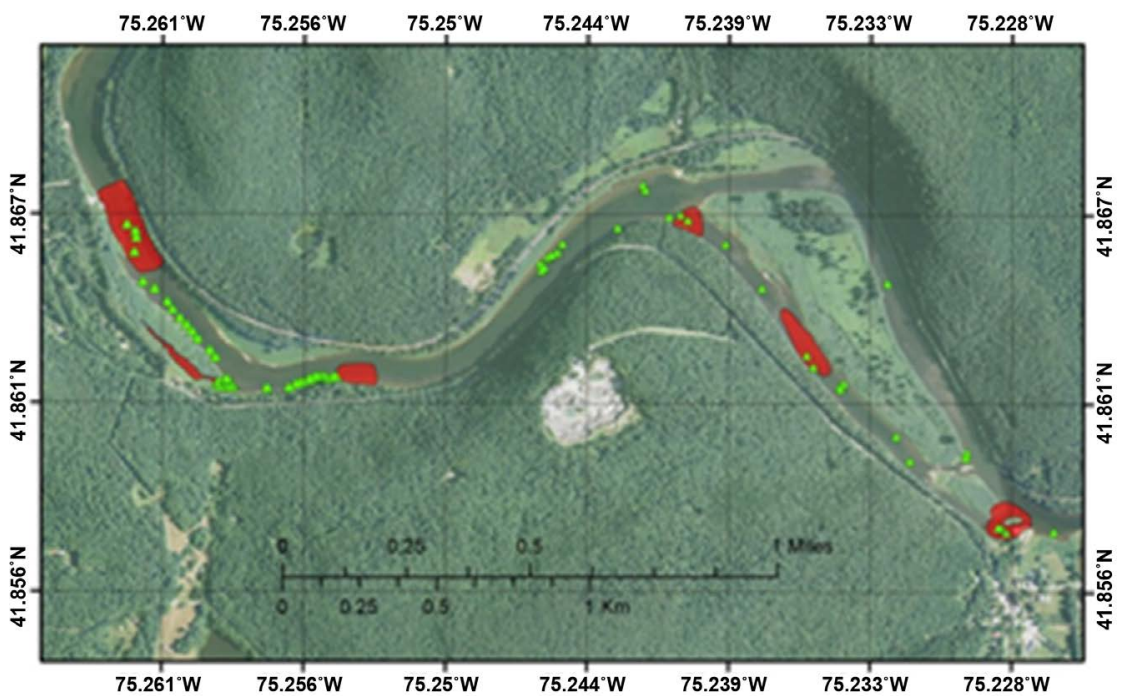

Figure 3. Map of a portion of the Upper Delaware River near Hancock, New York, showing SAV sampling points and polygons that were used for reference in the hyperspectral imagery analysis.

nearly completely black from the water surface, absorbing the infrared energy, any positive reflection is either an above water object, or, specular reflectance. Sunglint is demonstrated in Figure 4, which is ARCHER band 44 with a band center at $1006.594 \mathrm{~nm}$. The bright areas are specular reflectance artifacts that must be removed.

Several sunglint correction algorithms have been developed [42] [43] [44] [46]. Kay et al. [47] and Streher et al. [48] provide an in-depth review of these techniques. In general, these techniques have been developed for multispectral imagery and assume that: 1) Water leaving radiance is near zero in a near infrared (NIR) band, and any remnant brightness of atmospherically corrected data is due to sunglint, and 2) the level of sunglint estimated from the NIR band is linearly related to the glint contribution in the visible (VIS) bands. The algorithms use the signal response of a NIR spectral band from a deep-water part of an image to estimate sunglint contribution, which is then used to subtract from the visible bands [42] [43] [47]. Other sunglint correction methods developed for hyperspectral imagery are more relevant to this study. Kutser [44] developed an algorithm based on the $763 \mathrm{~nm}$ oxygen absorption band. The reflectance in this band is zero if atmospheric correction is effective, and any remnant signal is considered contribution from sunglint. However, this method is often too sensitive to atmospheric correction. Goodman et al. [46] developed a sunglint correction technique based on Lee et al. [49] that assumes reflectance approaches zero at $750 \mathrm{~nm}$. The algorithm permits greater than zero reflectance in shallow areas based on the reflectance measured at $640 \mathrm{~nm}$. Streher et al. [48] successfully applied the Goodman et al. [46] sunglint correction method to remove the noise from hyperspectral images in a lotic system.

This study also uses the Goodman et al. [46] sunglint correction technique to 


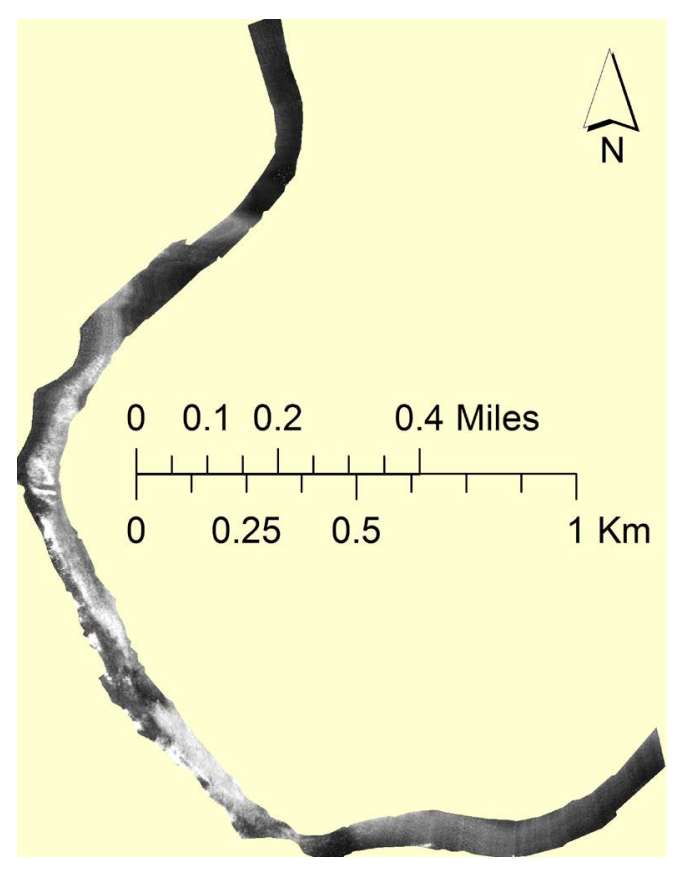

Figure 4. ARCHER band of a section of the Upper Delaware River at $1006 \mathrm{~nm}$ with the upland masked out, showing a substantial level of specular reflectance as indicated by the bright pixels.

remove the noise from the surface of the Delaware River and improve the radiometric quality of the ARCHER hyperspectral imagery for the detection of the SAV, because the technique was developed for use with hyperspectral imagery, is sensor-independent, and was successfully implemented in a lotic system [46].

The sunglint correction technique was applied after radiometric calibration of the ARCHER hyperspectral data from at sensor radiance to Top of Atmosphere (ToA) reflectance, and post QUAC atmospheric correction algorithm in ENVI software, which was applied to calibrate the data from ToA reflectance to surface reflectance. The input to the algorithm requires estimation of the above water remote sensing reflectance (Rrsraw (sr)-1) [48], which was calculated by multiplying the image cube by $\pi$ using ENVI Band Math syntax. Streher et al. [48] note that the sunglint correction is not wavelength dependent and is calculated as a constant offset for all wavelengths that is determined by the difference between Rrs at 640 and $750 \mathrm{~nm}$, based on the Goodman et al. [46] equations (Equation (1) and Equation (2)).

$$
\begin{gathered}
\operatorname{Rrs}(\lambda)=\operatorname{Rrsraw}(\lambda)-\operatorname{Rrsraw}(750)+\Delta \\
\Delta=0.000019+0.1[\operatorname{Rrsraw}(640)-\operatorname{Rrsraw}(750)]
\end{gathered}
$$

where $\operatorname{Rrs}(\lambda)$ is the sunglint corrected remote sensing reflectance image cube; Rrsraw $(\lambda)$ is the above water remote sensing reflectance image cube; Rrsraw (750) is the above water remote sensing reflectance at $750 \mathrm{~nm}$; Rrsraw (640) is the above water remote sensing reflectance at $640 \mathrm{~nm}$; and $\Delta$ is the offset calculated using Equation (1) that is added to each wavelength; and 0.000019 and 0.1 are the constants. Once the sunglint correction is applied, the deglinted image 
cube $\operatorname{Rrs}(\lambda)$ is divided by $\pi$ to convert it back to surface reflectance [46]. The ARCHER hyperspectral imagery acquired for this study did not contain bands centered on 640 and $750 \mathrm{~nm}$. Thus, two alternate bands, 644.73 and $749.79 \mathrm{~nm}$, respectively, were used to correct the sunglint on the Delaware River present in the imagery.

The spectral profile of several of the common SAV species, and Didymo, were collected with an Analytical Spectral Devices (ASD), (ASDI, Boulder, Colorado) field spectrometer during the several field visits. Spectral collection was accomplished on species immediately after they were extracted from the water column and some spectra were collected in situ, although this proved to be difficult and often not successful due to the logistics of moving the spectrometer on a floating platform through flowing water and the inherent difficulties collecting spectra in the water column. Examples of SAV and Didymo spectra are shown in Figure 5 below.

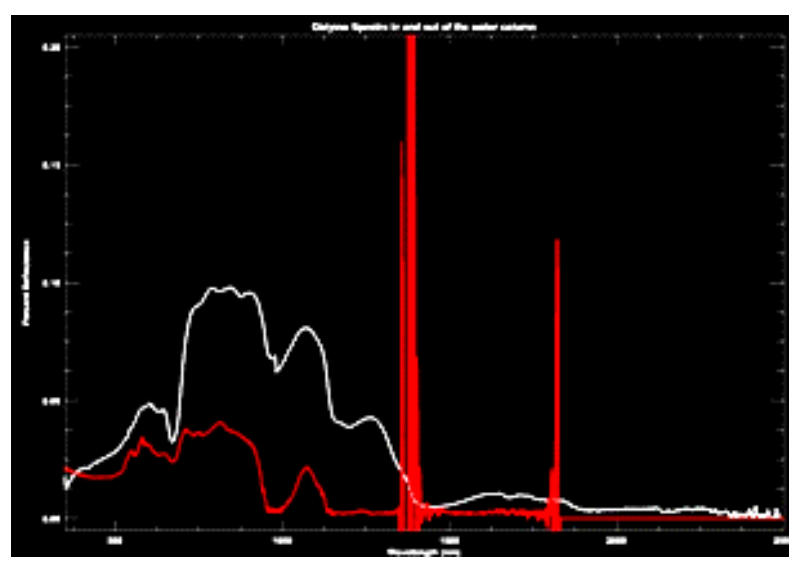

(A)

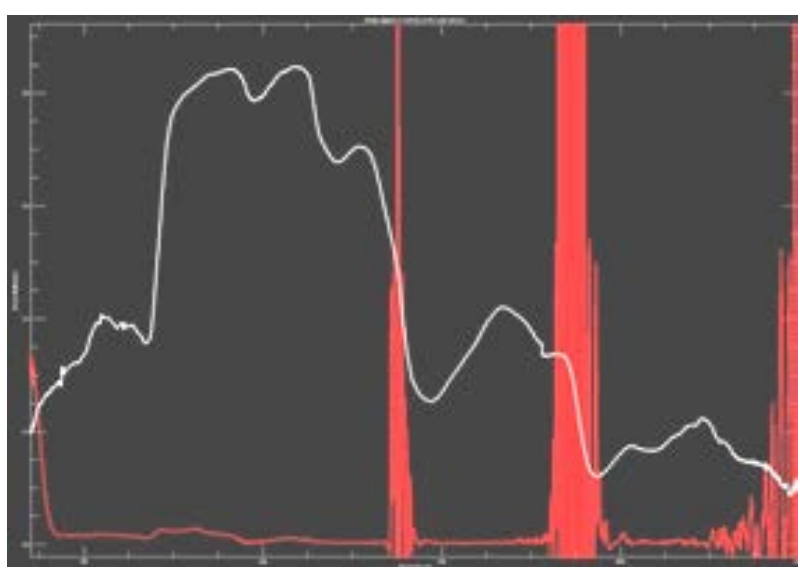

(B)

Figure 5. (A) An example of field spectral data of the invasive algae Didymosphenis geminate both in (red) the water column and out (white) showing the reduction in features caused by light attenuation and scattering caused by 3 inches of water; (B) SAV spectra (Elodea canadensis) collected with a field spectrometer; white - OUT of the water column and, red -IN the water column showing the inherent problems with reduced reflectance profile of light through the flowing water. 


\section{Analysis and Preliminary Results}

\subsection{Sunglint Removal}

The sunglint removal algorithm from Goodman et al. [46] and described in Section 3.2.1 resulted in a vastly Improved image data set. Figure 6 shows a portion of the river with the original imagery, the sunglint demonstrated in the infrared, and the color image after sunglint removal.

\subsection{Upland Vegetation Masking}

A number of conventional hyperspectral image processing strategies were first attempted. Laboratory derived spectra of SAV from the UPDE were averaged ( $\sim 10$ for each of the 13 species), compiled into a spectral library, and then, the spectral range of the laboratory spectra was resampled to match the spectral range of the ARCHER data (500 - $1000 \mathrm{~nm}$ ). A series of standard hyperspectral image processing techniques were attempted, including the Spectral Hourglass Wizard (SHW), Spectral Angle Mapper (SAM), Spectral Mixture Analysis (SMA), and Spectral Feature Fitting (SFF) along with a K-means unsupervised clustering algorithm. None of these methods returned viable classification results within the river reach. The relatively weak reflectance signatures of submerged vegetation were likely overwhelmed statistically by the strong upland reflectance features. Subsequently, all upland areas were masked and classification was again attempted on water column pixels only, without the confusion of upland endmembers. This method returned viable results that are demonstrated in Figure 7.

\subsection{Hyperspectral Image Processing and Classification}

Several image analysis techniques were applied to the ARCHER hyperspectral

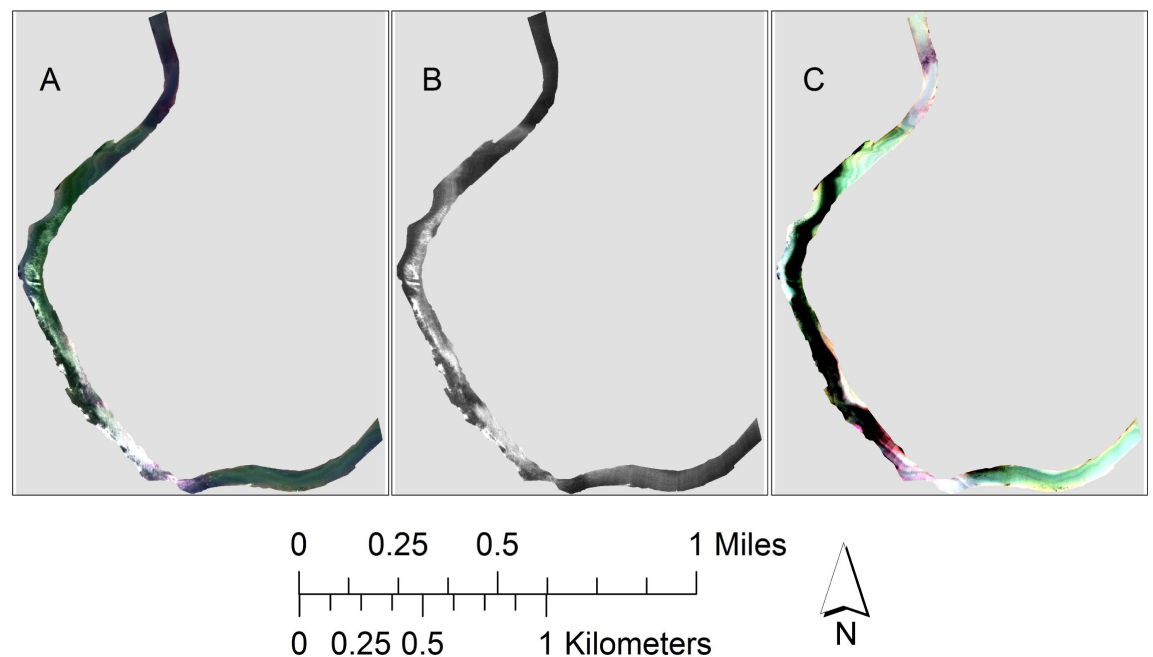

Figure 6. ARCHER hyperspectral imagery showing part of the Upper Delaware River: (A) Color composite image shows sunglint; (B) the brighter tones in the near infrared band $44(1006.594 \mathrm{~nm})$ illustrate sunglint; and (C) sunglint has been corrected by using the sunglint correction algorithm [44]. 


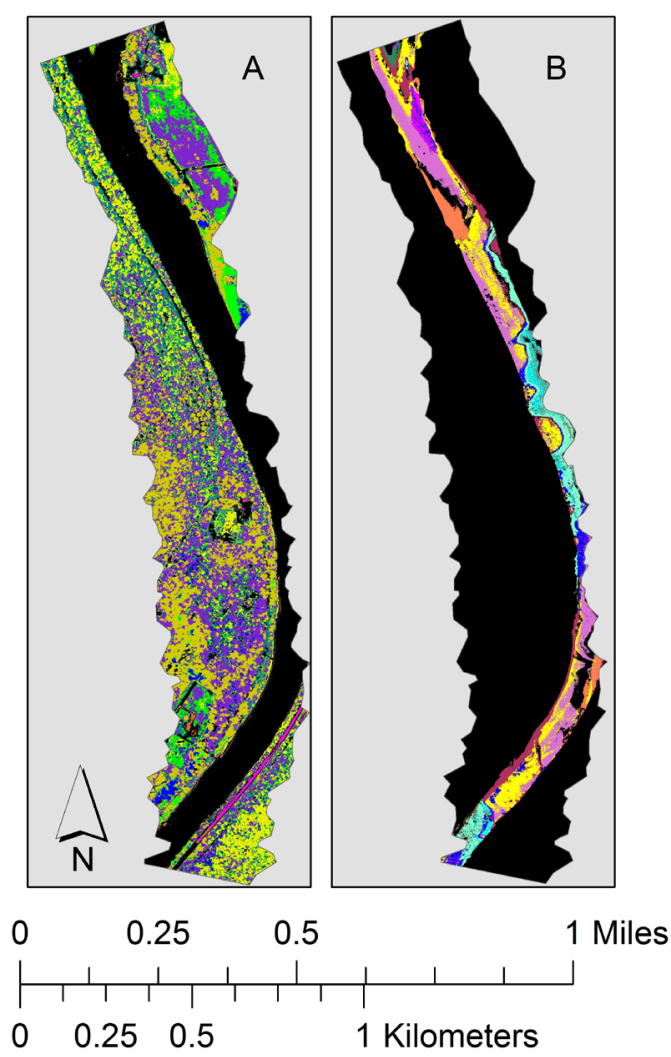

Figure 7. Automated classification results in the river with (left) and without (right) upland vegetation in the classification scheme. The strong upland vegetation reflectance features overwhelm the relatively weak submerged vegetation reflectance and return almost no in-stream results (left), but when the upland reflectance features are masked, in-stream classification results can be reliably obtained (right).

imagery in an effort to detect and map SAV in parts of the Delaware River. The image analysis techniques consisted of visual or manual interpretation combined with supervised classification, unsupervised classification and data transformation. Species level identification of the SAV, however, could not be consistently accomplished. Largely due to the variability of the water surface, the water column and constituents (e.g. silt, sediment, and detritus), and the river bottom. The best results were achieved by using reference SAV polygons collected by field personnel to train the Maximum Likelihood supervised classification.

Spectral Angle Mapper (SAM) supervised classification, which directly compares image spectra to known reference spectra, was unsuccessful in classifying the SAV species. Reference SAV spectra that were sampled at selected random locations in the field and those measured in the laboratory could not be matched to image pixel spectra. Furthermore, image-based sample areas of SAV (i.e. regions of interest) based on the GPS locations of field samples did not produce any results using SAM.

Although many image analysis techniques were applied to map the SAV in a part of the Delaware River, the best results were achieved by using a simple presence/absence classification strategy using the image endmembers of the SAV 
to train the Maximum Likelihood supervised classification. Of these results, individual macrophyte species identification could not be accomplished with any degree of statistical confidence. This likely due to a number of factors including the lack of unique spectral signatures between species, the greatly reduced reflectance intensity of light in the water column, and the variability of signatures caused by differing water depths, sediment, detritus and other constituents of water in a flowing system. However, the presence and absence of SAVs was mapped successfully using the Maximum Likelihood algorithm.

The automated SHW in the ENVI software was applied to map the SAV. First, the Minimum Noise Fraction Transform (MNF) was used to reduce imagery noise and data redundancy. Second, the Pure Pixel Index (PPI) was applied to locate and iteratively derive the most spectrally pure pixels or endmembers from the image. And finally, the SAM algorithm was employed to classify pixels in the image that contain each of the PPI selected endmembers. Very few pixels, which minimally coincided with the area of the reference samples, were produced as classification results by the SHW, but spectral or visual affirmation of the results was not possible. The SHW process was conducted on all bands initially. Then, it was applied to bands ranging from $505-689 \mathrm{~nm}$ (all visible bands). Additionally, using SHW with all the bands and only the visible bands, both the field and lab spectra were employed instead of the image-based PPI endmembers. The IsoData and $\mathrm{K}$-means unsupervised classification techniques were also used in an effort to map SAV. All of these methods produced nearly identical spectrally similar clusters or classes but were of only limited value.

A PCA approach, which also reduces data noise and redundancy, was also applied to shortest blue band $(504.655 \mathrm{~nm})$ and the longest green band (598.039 $\mathrm{nm}$ ) of the ARCHER image to map the SAV. The logic for the use of the PCA on these two visible (VIS) bands is simple: 1) Vegetation strongly reflects incident radiation in the near infrared (NIR) part of the spectrum, and conversely, water absorbs that region of the spectrum. Thus, the characteristic red edge, which is used by image analysts to detect vegetation, is subdued by the water above vegetation, confounding the strong vegetation NIR reflectance; 2) the shorter VIS wavelengths penetrate water relatively more than the NIR; and 3) the blue part of the spectrum is absorbed by vegetation for photosynthesis and the green part of the spectrum is reflected by the plant. The PCA analysis did produce favorable visual results; however, species level classification was problematic.

\subsection{Identification of Didymo germinata}

One of the main objectives of this study was the identification of the invasive algae, Didymo germinata. Using the reference Didymo spectra collected at a selected location in the Upper Delaware River, the SAM algorithm was applied to map the areal extent of Didymo from an ARCHER hyperspectral image at three varying processing levels (Figure 8): (A) An at sensor reflectance image, (B) an atmospherically corrected image, and (C) a sunglint removed or deglinted image. SAM did not produce a classification result for any of the three images with 


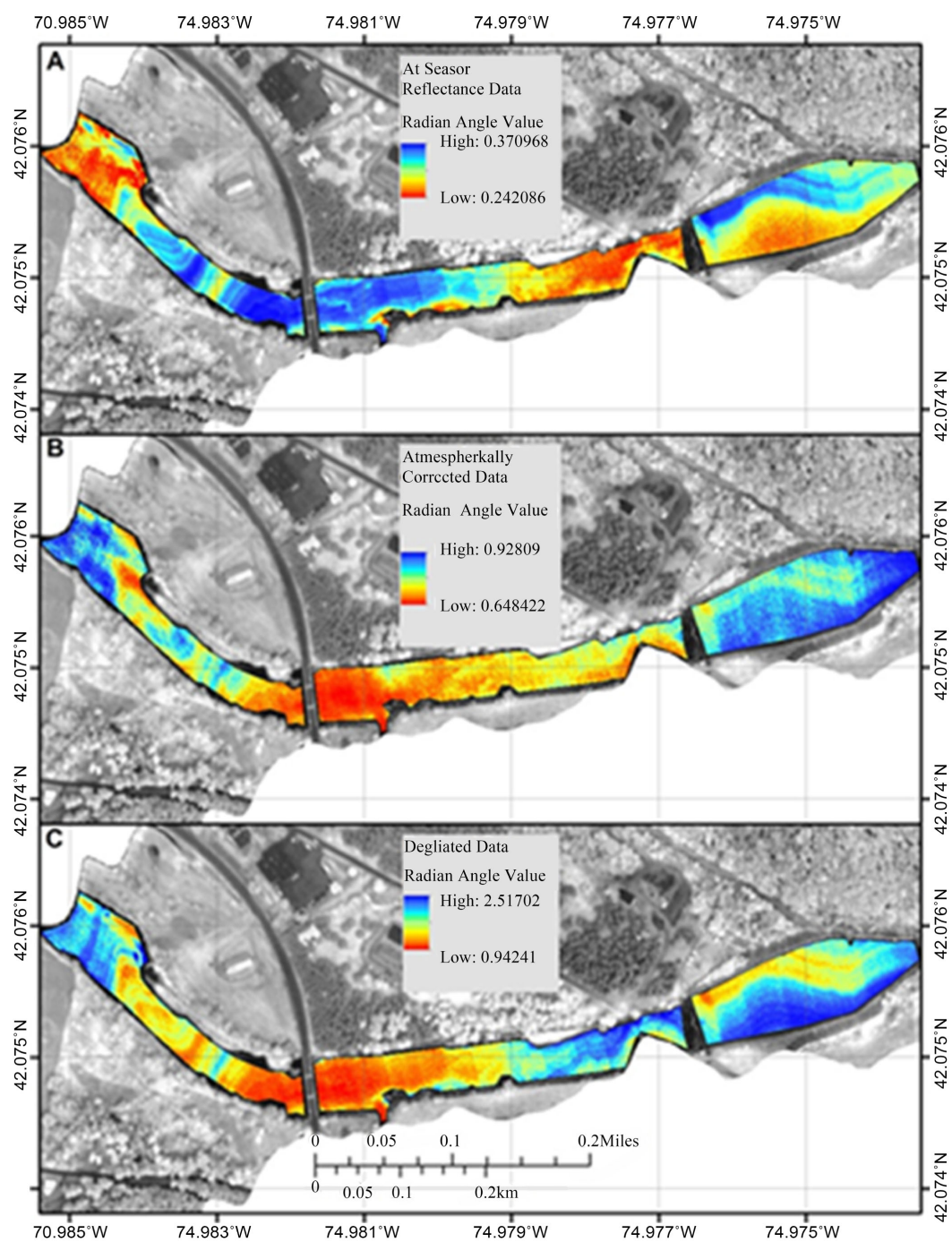

Figure 8. Spectral Angle Mapper (SAM) algorithm rule images produced from the same ARCHER hyperspectral image at three different processing levels. These rule images illustrate the similarity or radian angle value between the reference Didymo spectrum and the spectrum of the imaging spectroscopy data. (A) Rule image calculated from an at sensor reflectance image; (B) rule image computed from an atmospherically corrected image, and $(C)$ rule image calculated from a sunglint removed image. Analysis of the rule images from $A$ to $B$, and $B$ to $C$, reveal that the radian angle values between the reference Didymo and image spectrums increase at each processing level.

the standard 0.10 radian angle value threshold. Analysis of the rule images produced by SAM, which represent the similarity or radian angle values between the reference Didymo spectrum and the spectrum of each of the three uniquely processed imaging spectroscopy data, revealed a distinct pattern. Specifically, the assumption is that as the image cube is, calibrated to at sensor reflectance, atmospherically corrected, and finally, the sunglint is removed from the water-surface; instrumental, atmospheric and water surface distortions are minimized or rectified. Under these assumptions, SAM should produce a closer match between the reference Didymo spectra and the image spectrum at each 
progressive processing level. In contrast, with each advance in processing of the image cube, the radian angle value calculated by SAM between the reference and the image spectrum increased (Figure 8).

These results indicate that at each additional processing level, the reference and image spectrum became more dissimilar, where the two spectrums were expected to match more closely after each image processing level. Furthermore, a change in radian angle values is observed in the SAM output rule images of both the QUAC atmospherically corrected and the sunglint corrected images (Figure 9). Specifically, pixels that were a closer match to the reference Didymo spectrum in the at sensor reflectance rule image, changed to less similar matches; and pixels that were less similar became more similar to the reference spectrum.

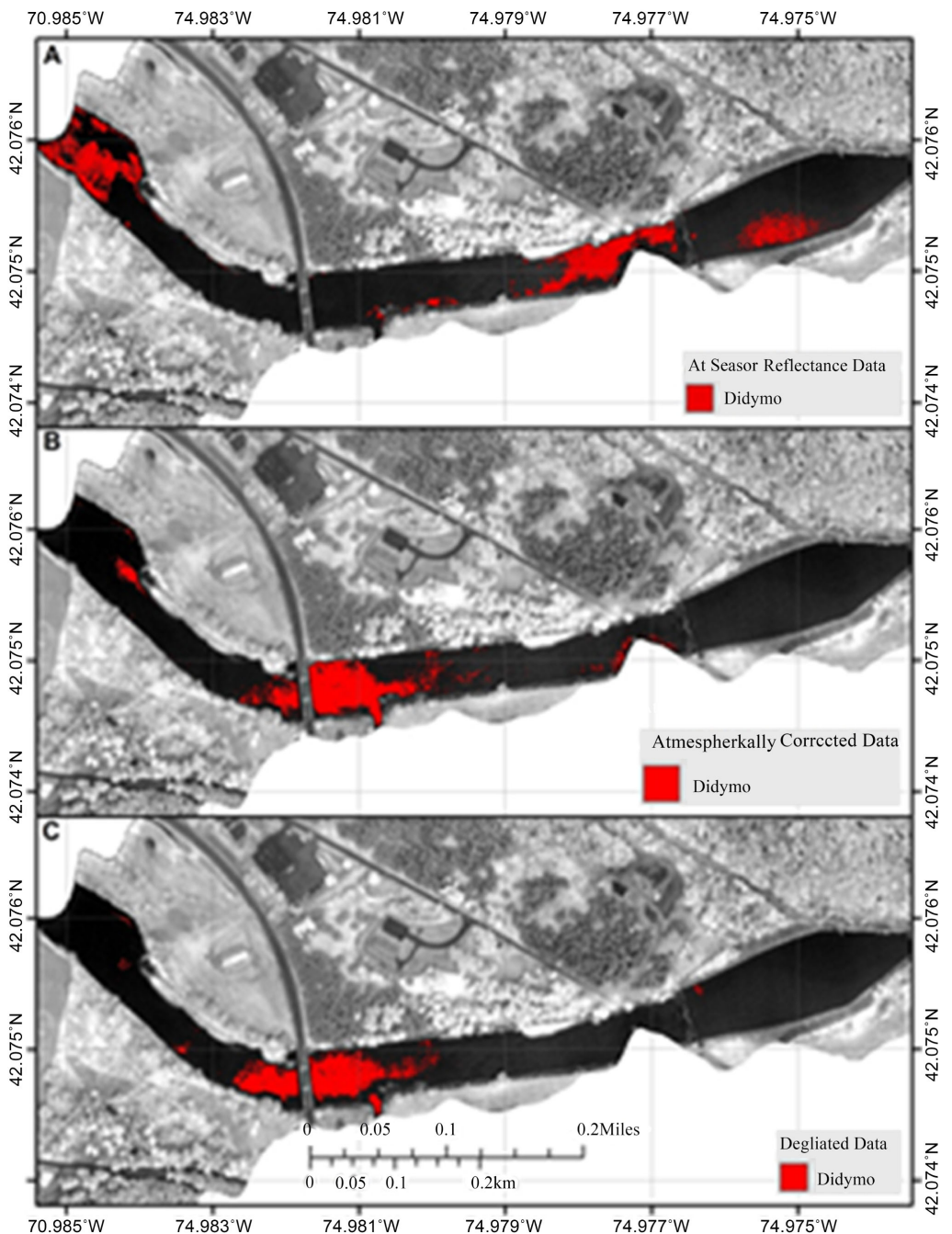

Figure 9. Maps showing Didymo classification interpreted from SAM rule images (i.e. similarity between reference Didymo and image spectrums calculated from: (A) an at sensor reflectance image, (B) an atmospherically corrected image, and (C) a sunglint removed image. Field observations by U.S. Geological Survey and the National Park Service scientists confirm that the Didymo map produced from A provides the best approximation of the location and extent of the Didymo in this section of Upper Delaware River. 
Nevertheless, there is potential for the identification and mapping of Didymo via imaging spectroscopy. While the above-mentioned increase and change in the radian angle values between the reference Didymo and the three image spectrums, are not readily explainable and require further investigation; field observations by U.S. Geological Survey and the National Park Service scientists confirm that the Didymo map produced from the at sensor reflectance rule image provides the best approximation of the location and extent of the Didymo in the Upper Delaware River (Figure 8). Furthermore, rule images B and C, show pixels that were a closer match to the reference Didymo spectrum in the A rule image, changed to less similar matches; and pixels that were less similar became more similar to the reference spectrum.

\subsection{Preliminary Accuracy Assessment}

In spite of the many operational problems with SAV mapping in this application, an accuracy assessment of a subset of the river was accomplished in order to establish a rough level of accuracy that one might expect in these conditions. Ground truth was provided by the in-situ surveys conducted by the authors. The most basic of assessments was conducted to assess presence or absence of SAV in a particular stretch of the river.

Overall Accuracy $=(11009 / 24231) 45.4335 \%$

Kappa Coefficient $=0.2929$

\begin{tabular}{cccc}
\hline \multicolumn{4}{c}{ Ground Truth (Pixels) } \\
Class & Non_SAV & SAV & Total \\
\hline Unclassified & 7482 & 5735 & 13217 \\
Non_SAV & 5775 & 1 & 5776 \\
SAV & 4 & 5234 & 5238 \\
Total & 13261 & 10970 & 24231 \\
& Ground Truth (Percent) & & \\
Class & Non_SAV & SAV & Total \\
Unclassified & 56.42 & 52.28 & 54.55 \\
Non_SAV & 43.55 & 0.01 & 23.84 \\
SAV & 0.03 & 47.71 & 21.62 \\
Total & 100.00 & 100.00 & 100.00 \\
\hline
\end{tabular}

\section{Conclusions and Discussion}

Attempting to utilize hyperspectral imagery to map SAVs in shallow, flowing, winding riverine systems presents a number of unique problems, not only for imagery analysis but also for acquisition, logistics and field work. This study has identified some of those unique problems and, to some extent, provided a workable solution, although more research needs to be done.

Important results of this study include: 
1) Masking upland vegetation. Reflectance of vegetation below the water surface is measurable but often very weak because of the absorption and attenuation of light in the water column. Relative to upland materials that are directly reflecting sunlight, subsurface water targets only reflect a small portion of incoming energy. More importantly, most image processing and classification approaches use parametric statistics that treat the entire scene as the statistical "universe" and therefore weak, under water features are overwhelmed or completely omitted because of their weak signal.

2) Spectral profiles above and below water surface. Similarly, spectral profiles of underwater targets are altered and cannot be simply replaced by spectra taken by samples removed from the water column. Spectra collected just above the water surface or spectra collected underwater with special attachments may be required to determine an accurate relationship between local and overhead spectral relationships.

3) Species identification was not possible in this study but reasonable results for the presence or absence of SAVs was accomplished using a supervised maximum likelihood classifier.

4) Spectral identification of Didymo was promising but needs more testing and validation as results can also be attributed to the morphological characteristics of the river channel where Didymo was predominantly detected. It is unclear how much spectral information (as opposed to spatial information) contributed to this identification.

5) Hyperspectral data collection over winding lotic systems is problematic and inevitably introduces specular reflection issues. Removal of specular reflection artifacts, also known as "sunglint" is an absolute requirement for processing in such imagery acquisition scenarios but also comes at a cost of sometimes over-correcting the spectral signal in riffles and rapids.

6) Standard hyperspectral processing may not always be the best approach in some situations. The images that were processed to at-sensor reflectance and the de-glinting algorithm were clearly not as good as the basic rule image from the Spectral Angle Mapper process. It is clear that, in special situations such as Didymo in riffles and rapids, the actual spectral signature can be lost by over-processing of the image data.

7) A better understanding of the above, near-surface and underwater spectral signals would be a great enhancement to hyperspectral analysis of SAVs in lotic shallow systems.

Future research in this area should place a premium on the viewing geometry and sun angle of hyperspectral collections. The emergence of unmanned aerial system (UAS) technology has the promise of providing a much more suitable collection environment for all the problems that can be encountered in winding lotic environments.

\section{Acknowledgements}

This project was funded by the Land Remote Sensing Program of the Climate 
and Land Use Mission Area of U.S. Geological Survey, with support from the U.S. Department of the Interior's Water SMART program. Any use of trade, firm, or product names is for descriptive purposes only and does not imply endorsement by the U.S. Government. Data used in support of the conclusions presented herein are available as a USGS data release in Slonecker et al. (2018) [50].

\section{Conflicts of Interest}

The authors declare no conflicts of interest regarding the publication of this paper.

\section{References}

[1] National Park Service, Delaware Water Gap Management (2015) http://www.nps.gov/dewa/learn/management/index.htm

[2] Newman, R.M. (1991) Herbivory and Detritivory on Freshwater Macrophytes by Invertebrates: A Review. Journal of the North American Benthological Society, 10, 89-114. https://doi.org/10.2307/1467571

[3] Gregg, W.W. and Rose, F.L. (1985) Influences of Aquatic Macrophytes on Invertebrate Community Structure, Guild Structure, and Microdistribution in Streams. Hydrobiologia, 128, 45-56. https://doi.org/10.1007/BF00008939

[4] van Snik Gray, E., Ross, R.M. and Bennett, R.M. (2005) Bioassessment of Fish Communities of the Upper Delaware River. Northeastern Naturalist, 12, 203-216. https://doi.org/10.1656/1092-6194(2005)012[0203:BOFCOT]2.0.CO;2

[5] Bowden, W.B., Glime, J.M. and Riis, T. (2017) Macrophytes and Bryophytes. In: Methods in Stream Ecology, Volume 1, 3rd Edition, 243-271.

[6] Kunsman, J. (1994) A Survey of the Aquatic Vascular Plants of the Upper Delaware River. Unpublished Report to the National Park Service, Pennsylvania Science Office of the Nature Conservancy, Middletown, 322.

[7] Orth, R.J. (1992) A Perspective on Plant-Animal Interactions in Seagrasses: Physical and Biological Determinants Influencing Plant and Animal Abundance. Plant-Animal Interactions in the Marine Benthos. Clarendon Press, Oxford, 147-164.

[8] Costanza, R., et al. (1998) The Value of the World's Ecosystem Services and Natural Capital. Ecological Economics, 1, 3-15. https://doi.org/10.1016/S0921-8009(98)00020-2

[9] Koch, E.W. (2001) Beyond Light: Physical, Geological, and Geochemical Parameters as Possible Submersed Aquatic Vegetation Habitat Requirements. Estuaries, 24, 1-17. https://doi.org/10.2307/1352808

[10] Bal, K., et al. (2011) How Do Macrophyte Distribution Patterns Affect Hydraulic Resistances? Ecological Engineering, 37, 529-533. https://doi.org/10.1016/j.ecoleng.2010.12.018

[11] Kemp, W., et al. (2005) Eutrophication of Chesapeake Bay: Historical Trends and Ecological Interactions. Marine Ecology Progress Series, 303, 1-29. https://doi.org/10.3354/meps303001

[12] Heck, K. and Valentine, J. (2007) The Primacy of Top-Down Effects in Shallow Benthic Ecosystems. Estuaries and Coasts, 30, 371-381. 
https://doi.org/10.1007/BF02819384

[13] Ross, R.M., Bennett, R.M. and Johnson, J.H. (1997) Habitat Use and Feeding Ecology of Riverine Juvenile American Shad. North American Journal of Fisheries Management, 17, 964-974. https://doi.org/10.1577/1548-8675(1997)017<0964:HUAFEO>2.3.CO;2

[14] Walter III, J. and Olney, J. (2003) Feeding Behavior of American Shad During Spawning Migration in the York River, Virginia. American Fisheries Society Symposium, 35, 185-192.

[15] Bushmann, P.J. and Ailstock, M.S. (2006) Antibacterial Compounds in Estuarine Submersed Aquatic Plants. Journal of Experimental Marine Biology and Ecology, 331, 41-50. https://doi.org/10.1016/j.jembe.2005.10.005

[16] Silva, T.S., et al. (2008) Remote Sensing of Aquatic Vegetation: Theory and Applications. Environmental Monitoring and Assessment, 140, 131-145. https://doi.org/10.1007/s10661-007-9855-3

[17] Legleiter, C.J. (2003) Spectrally Driven Classification of High Spatial Resolution, Hyperspectral Imagery: A Tool for Mapping In-Stream Habitat. Environmental Management, 32, 399-411. https://doi.org/10.1007/s00267-003-0034-1

[18] Marcus, W.A. (2002) Mapping of Stream Microhabitats with High Spatial Resolution Hyperspectral Imagery. Journal of Geographical Systems, 4, 113-126. https://doi.org/10.1007/s101090100079

[19] Marcus, W.A. and Fonstad, M.A. (2008) Optical Remote Mapping of Rivers at Sub-Meter Resolutions and Watershed Extents. Earth Surface Processes and Landforms, 33, 4-24. https://doi.org/10.1002/esp.1637

[20] Kinzel, P.J., et al. (2007) Evaluation of an Experimental LiDAR for Surveying a Shallow, Braided, Sand-Bedded River. Journal of Hydraulic Engineering, 133, 838-842. https://doi.org/10.1061/(ASCE)0733-9429(2007)133:7(838)

[21] McKean, J.A., Isaak, D.J. and Wright, C.W. (2008) Geomorphic Controls on Salmon Nesting Patterns Described by a New, Narrow-Beam Terrestrial-Aquatic Lidar. Frontiers in Ecology and the Environment, 6, 125-130. https://doi.org/10.1890/070109

[22] Hall, R.K., et al. (2009) Quantifying Structural Physical Habitat Attributes using LIDAR and Hyperspectral Imagery. Environmental Monitoring and Assessment, 159, 63-83. https://doi.org/10.1007/s10661-008-0613-y

[23] Milton, N., Eiswerth, B. and Ager, C. (1991) Effect of Phosphorus Deficiency on Spectral Reflectance and Morphology of Soybean Plants. Remote Sensing of Environment, 36, 121-127. https://doi.org/10.1016/0034-4257(91)90034-4

[24] Milton, N.M., et al. (1983) Remote Detection of Metal Anomalies on Pilot Mountain, Randolph County, North Carolina. Economic Geology, 78, 605-617. https://doi.org/10.2113/gsecongeo.78.4.605

[25] Rock, B., et al. (1986) Remote Detection of Forest Damage. BioScience, 36, 439-445. https://doi.org/10.2307/1310339

[26] Goetz, S., Gardiner, N. and Viers, J. (2008) Monitoring Freshwater, Estuarine and Near-Shore Benthic Ecosystems with Multi-Sensor Remote Sensing: An Introduction to the Special Issue. Remote Sensing of Environment, 112, 3993-3995. https://doi.org/10.1016/j.rse.2008.05.016

[27] Dennison, W.C. (2009) Global Trajectories of Seagrasses, the Biological Sentinels of Coastal Ecosystems. In: Duarte, C.M., Ed., Global Loss of Coastal Habitats. Rates, Causes and Consequences, Fundación BBVA, Madrid, 89-106. 
[28] Orth, R.J. and Moore, K.A. (1984) Distribution and Abundance of Submerged Aquatic Vegetation in Chesapeake Bay: An Historical Perspective. Estuaries, 7, 531-540. https://doi.org/10.2307/1352058

[29] Wetzel, R. and Penhale, P. (1983) Production Ecology of Seagrass Communities in the Lower Chesapeake Bay [Ruppiamaritima, Zostera Marina, Virginia]. Marine Technology Society Journal, 17, 22-31.

[30] Stevenson, J. (1988) Comparative Ecology of Submersed Grass Beds in Freshwater, Estuarine, and Marine Environments1. Limnology and Oceanography, 33, 867-893. https://doi.org/10.4319/lo.1988.33.4part2.0867

[31] Williams, D.J., et al. (2003) Preliminary Investigation of Submerged Aquatic Vegetation Mapping using Hyperspectral Remote Sensing. Environmental Monitoring and Assessment, 81, 383-392. https://doi.org/10.1023/A:1021318217654

[32] Bostater Jr., C.R., et al. (2004) Hyperspectral Remote Sensing Protocol Development for Submerged Aquatic Vegetation in Shallow Waters. Proceeding SPIE 5233, Remote Sensing of the Ocean and Sea Ice 2003, Barcelona, 26 February 2004.

[33] Underwood, E., et al. (2006) Mapping Invasive Aquatic Vegetation in the Sacramento-San Joaquin Delta using Hyperspectral Imagery. Environmental Monitoring and Assessment, 121, 47-64. https://doi.org/10.1007/s10661-005-9106-4

[34] Hestir, E.L., et al. (2008) Identification of Invasive Vegetation using Hyperspectral Remote Sensing in the California Delta Ecosystem. Remote Sensing of Environment, 112, 4034-4047. https://doi.org/10.1016/j.rse.2008.01.022

[35] Adam, E., Mutanga, O. and Rugege, D. (2010) Multispectral and Hyperspectral Remote Sensing for Identification and Mapping of Wetland Vegetation: A Review. Wetlands Ecology and Management, 18, 281-296. https://doi.org/10.1007/s11273-009-9169-Z

[36] Becker, B.L., Lusch, D.P. and Qi, J. (2005) Identifying Optimal Spectral Bands from in Situ Measurements of Great Lakes Coastal Wetlands using Second-Derivative Analysis. Remote Sensing of Environment, 97, 238-248. https://doi.org/10.1016/j.rse.2005.04.020

[37] Becker, B.L., Lusch, D.P. and Qi, J. (2007) A Classification-Based Assessment of the Optimal Spectral and Spatial Resolutions for Great Lakes Coastal Wetland Imagery.

Remote Sensing of Environment, 108, 111-120.

http://www.nps.gov/dewa/learn/management/index.htm https://doi.org/10.1016/j.rse.2006.11.005

[38] Civil Air Patrol (2009) ARCHER for Coimmanders Briefing-Acrobat Format. https://coloradowingcap.org/Portals/0/ColoSpringsCadet/ARCHER_fact_sheet_647 9189EDBB60.pdf?ver=2009-07-20-191746-083

[39] Bernstein, L.S., et al. (2005) A New Method for Atmospheric Correction and Aerosol Optical Property Retrieval for VIS-SWIR Multi- and Hyperspectral Imaging Sensors: QUAC (Quick Atmospheric Correction). DTIC Document, Spectral Sciences Inc Burlington, MA.

[40] Strakosch-Walz, K. (2000) Instruction Manual on Heritage Field Methodology: Documenting Ecological Communities. New Jersey Natural Heritage Program, Trenton, 86.

[41] Braun-Blanquet, J. (1932) Plant Sociology. The Study of Plant Communities, Plant Sociology. The Study of Plant Communities.

[42] Hedley, J., Harborne, A. and Mumby, P. (2005) Technical Note: Simple and Robust Removal of Sunglint for Mapping Shallow-Water Benthos. International Journal of 
Remote Sensing, 26, 2107-2112. https://doi.org/10.1080/01431160500034086

[43] Hochberg, E.J., Atkinson, M.J. and Andréfouët, S. (2003) Spectral Reflectance of Coral Reef Bottom-Types Worldwide and Implications for Coral Reef Remote Sensing. Remote Sensing of Environment, 85, 159-173. https://doi.org/10.1016/S0034-4257(02)00201-8

[44] Kutser, T., Tranvik, L. and Pierson, D.C. (2009) Variations in Colored Dissolved Organic Matter between Boreal Lakes Studied by Satellite Remote Sensing. Journal of Applied Remote Sensing, 3, Article ID: 033538.

[45] Doxani, G., et al. (2012) Shallow-Water Bathymetry over Variable Bottom Types using Multispectral Worldview-2 Image. International Archives of the Photogrammetry, Remote Sensing and Spatial Information Sciences, Melbourne, 25 August-1 September 2012, 159-164. https://doi.org/10.5194/isprsarchives-XXXIX-B8-159-2012

[46] Goodman, J.A., Lee, Z. and Ustin, S.L. (2008) Influence of Atmospheric and Sea-Surface Corrections on Retrieval of Bottom Depth and Reflectance using a Semi-Analytical Model: A Case Study in Kaneohe Bay, Hawaii. Applied Optics, 47, F1-F11. https://doi.org/10.1364/AO.47.0000F1

[47] Kay, S., Hedley, J.D. and Lavender, S. (2009) Sunglint Correction of High and Low Spatial Resolution Images of Aquatic Scenes: A Review of Methods for Visible and Near-Infrared Wavelengths. Remote Sensing, 1, 697-730. https://doi.org/10.3390/rs1040697

[48] Streher, A.S., et al. (2015) Sunglint Correction in Airborne Hyperspectral Images over Inland Waters. Revista Brasileira de Cartografia, 3, 1437-1449.

[49] Lee, Z., et al. (1999) Hyperspectral Remote Sensing for Shallow Waters: 2. Deriving Bottom Depths and Water Properties by Optimization. Applied Optics, 38, 3831-3843. https://doi.org/10.1364/AO.38.003831

[50] Slonecker, T., Kalaly, S., Furedi, M.A., and Kunsman, R. (2018) Upper Delaware River National Parks Hyperspectral Imagery Analysis of Submerged Aquatic Vegetation. U.S. Geological Survey Data Release, Reston. 